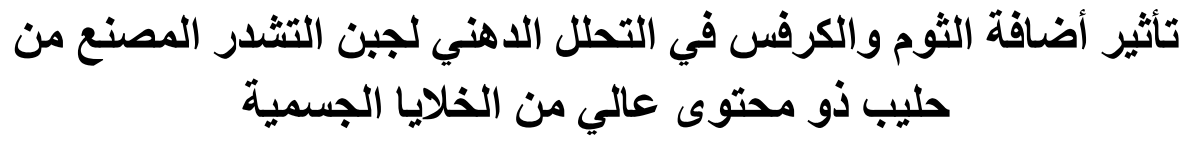

\title{
Effect of garlic and celery on lipolysis of chadder cheese with high somatic cells count
}

$$
\text { أزهار جواد الموسوي }
$$

Azhar J. AL- mosowy

Dept. Of Food sciences and biotechnology /college of Agriculture /Univ. of Baghdad

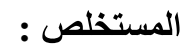

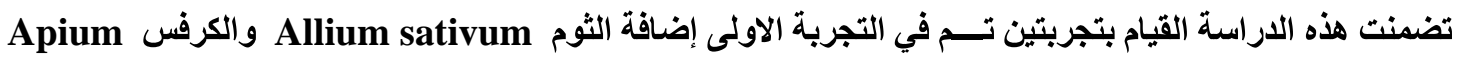
garaeolens

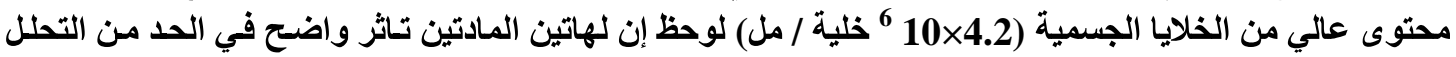

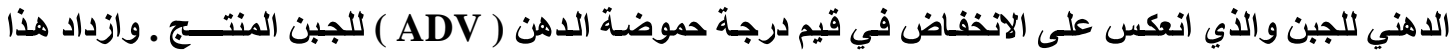

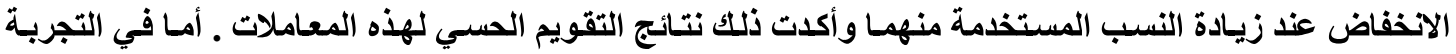

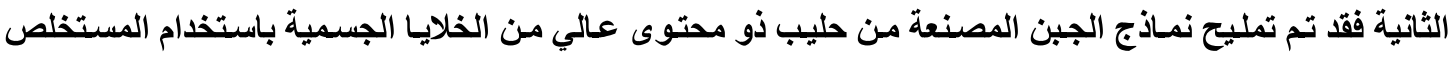

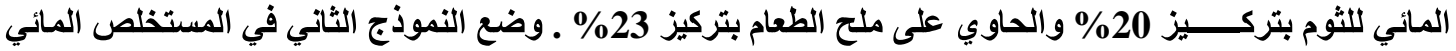

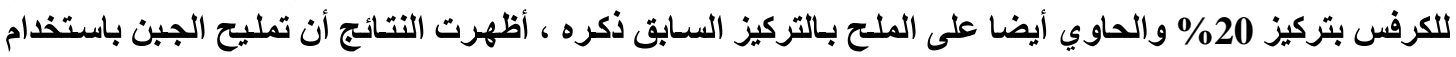

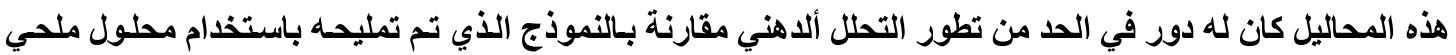

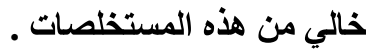

\section{Abstract}

The study include two experiments, in the 1st one, minced Garlic and Celery weradded performing at 5 and $20 \%$ to chadder cheese made from milk contained high somatic cells count $\left(4.2 \times 10^{6}\right.$ cell/ $\left.\mathrm{ml}\right)$, it was noted that these materials had a significant effect on preventiy lipolysis in cheese which was appeared through decreasing the Acid Degrees Value (ADV) of cheese samples contained Garlic and Celery. This decrease in values were fallowed by increasing the percentages of these materials and which was assured by the sensory evaluation. In second experiment two, chadder cheese samples contained high somatic cells count were brined in $23 \%$ solution plus $20 \%$ Garlic or Celery. Data of lipolysis also showed that these treatments prevented lipolysis comparing to cheese samples brined without adding minced Garlic and Celery. 
يعد دهن الحليب المادة الأساس (substrate) التي يمكن أن تنتج منها نكهة الجبن المثالية، من خلال تحرر الأحماض

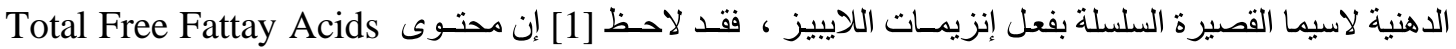
(TFFA)

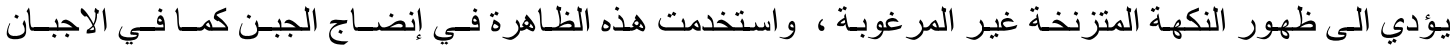

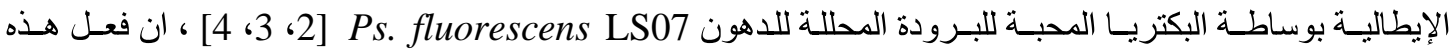

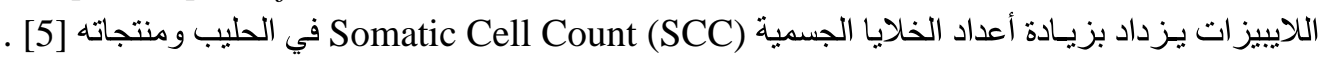

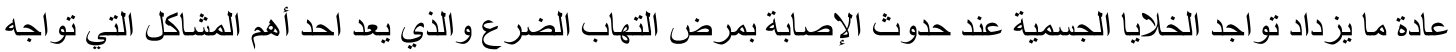

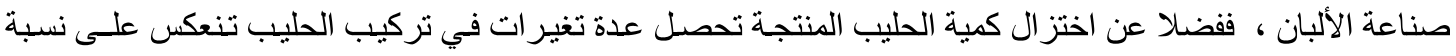

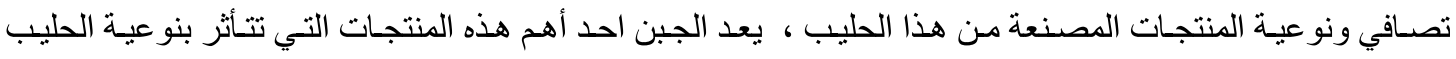

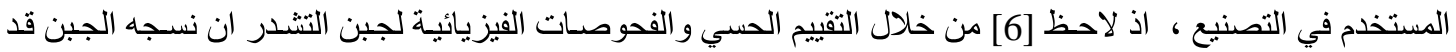

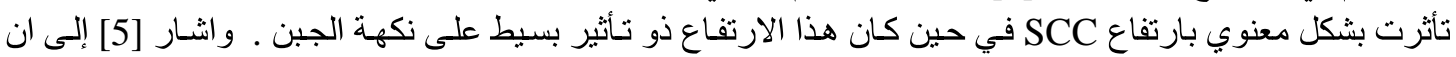

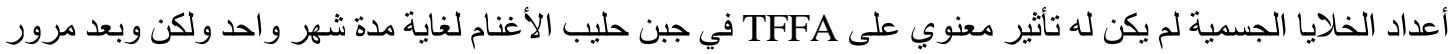

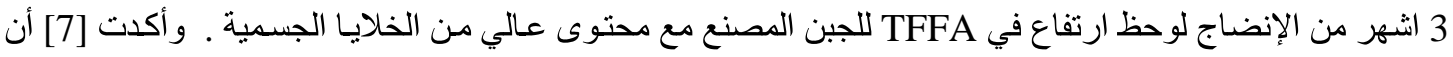

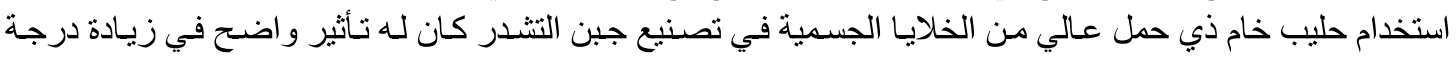
التعلل الدهني لنماذج الجبن المصنعة منه . الكرفس - (Apium graveolens)- celery وهو احد انواع العائلة الخيمية [8] يحتوي في تركيبه على أيون الحديد

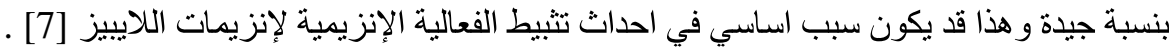

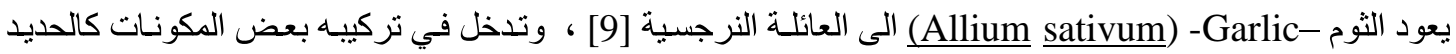

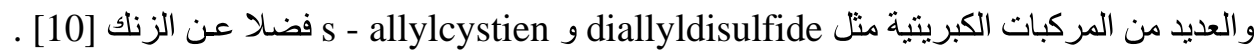

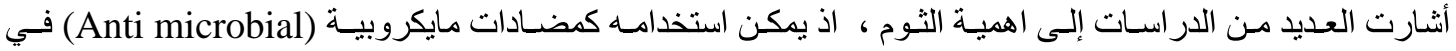

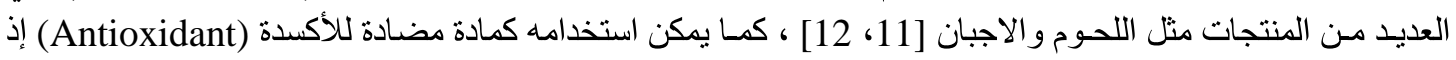

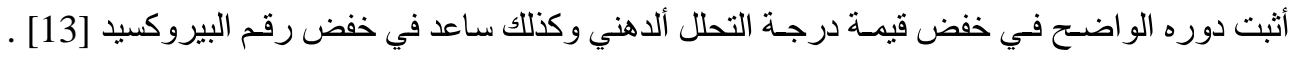

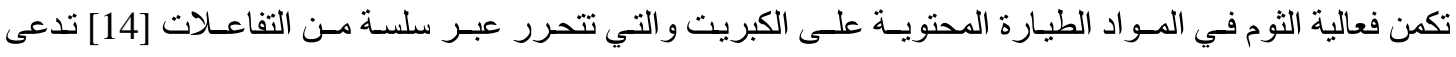

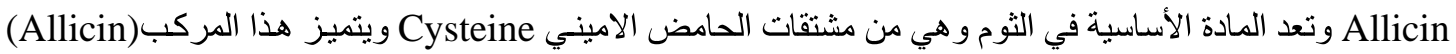

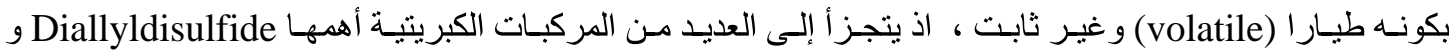

diallyltrisulfide

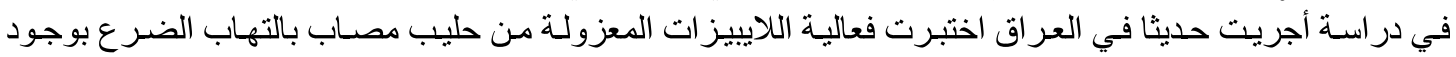

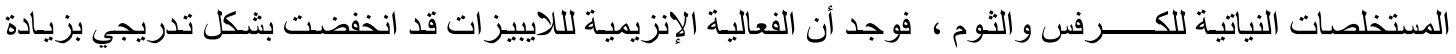

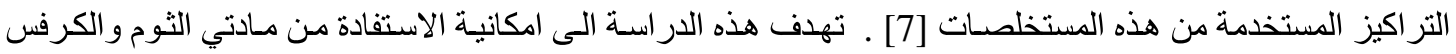

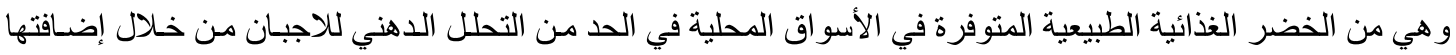

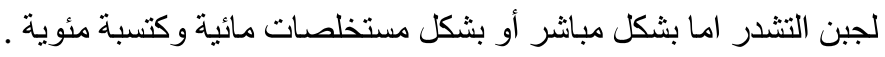

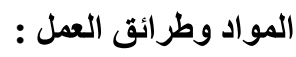
تحضير المواد الاساس

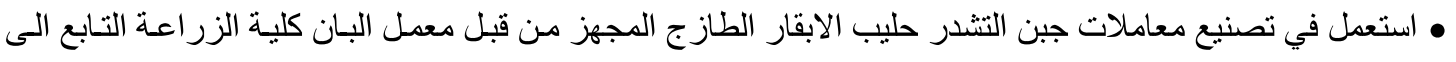

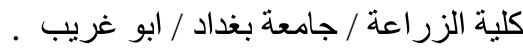

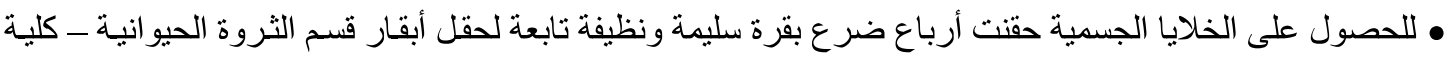

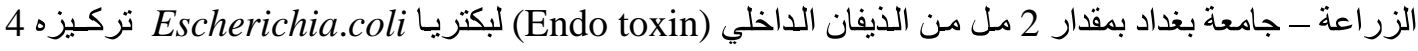

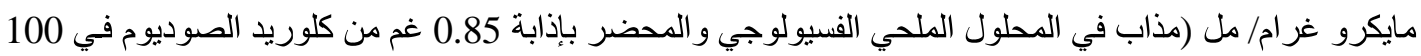

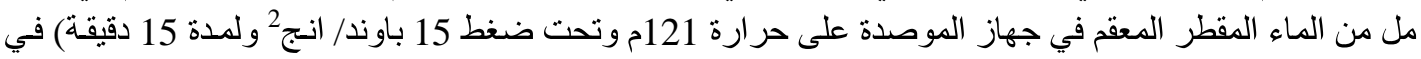

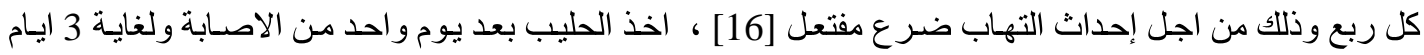

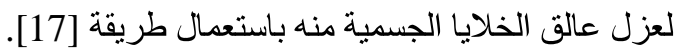


• حضر الحليب الخام المعامل لأجل تصنيع جبن التشدر وذللك بأضافة محلول عالق الخلايا الجسمية المحضر في الفقرة

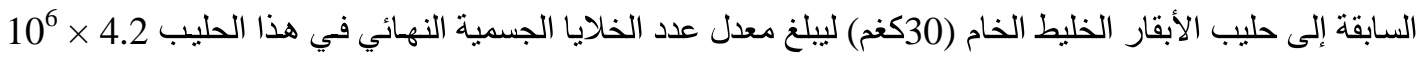

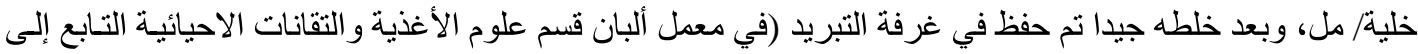

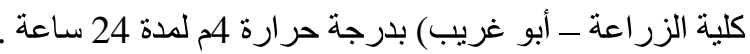

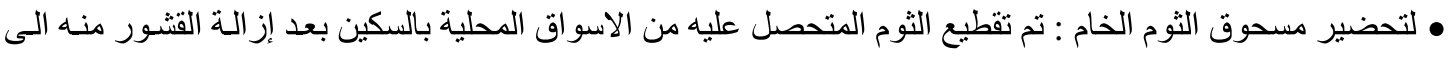
اجز اء صغيرة جدا. • وحضر مسحوق الكرفس الخام بثرمه باستخدام السكين العادي.

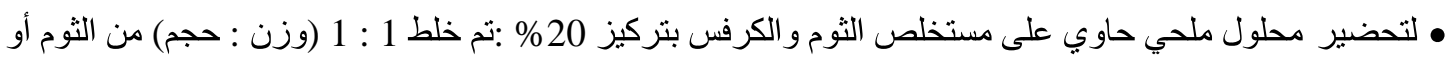

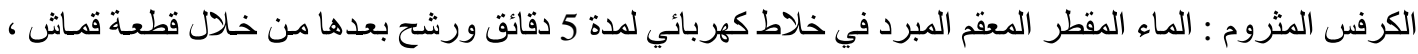

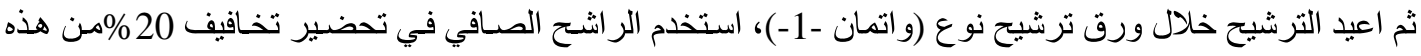

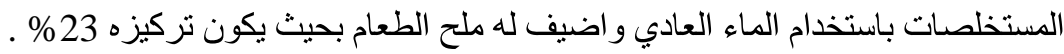

التجربة الأولى البنى

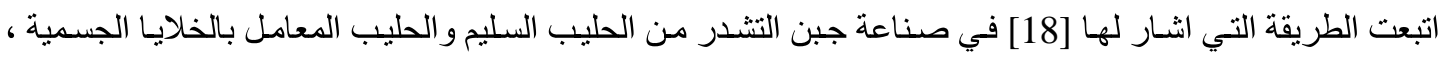

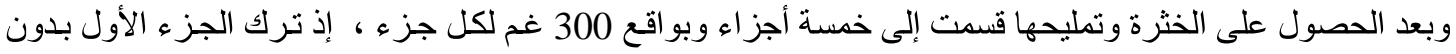

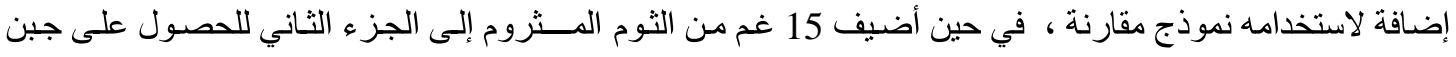

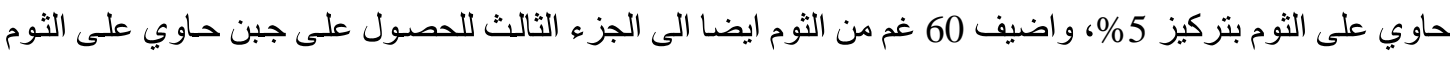

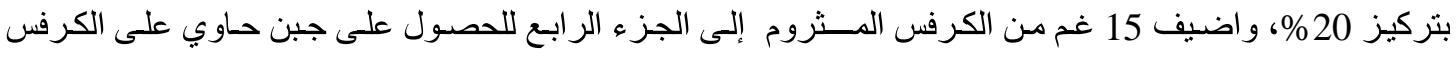

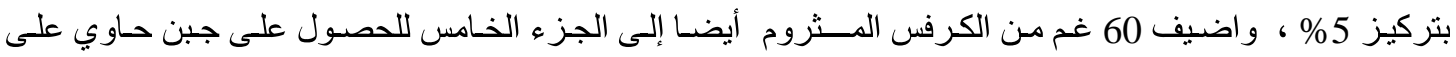

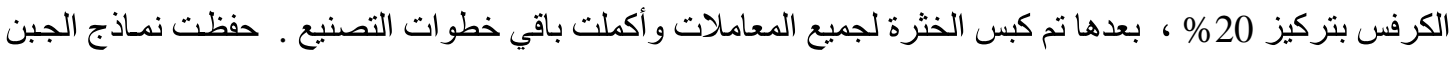

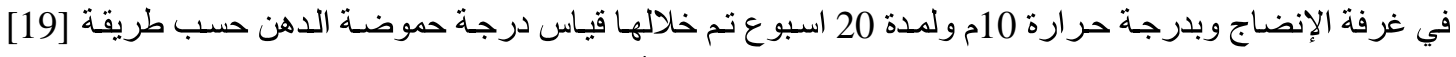

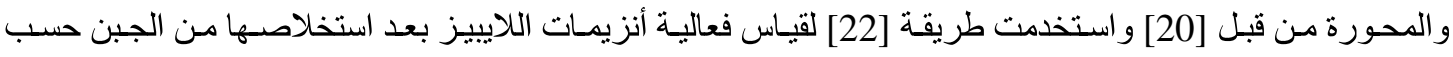

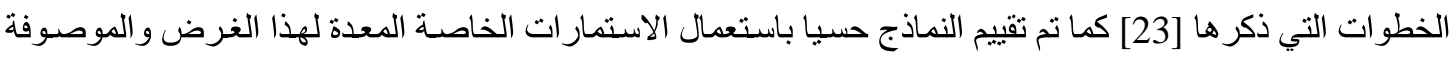
من قبل [21] [اتخطوات التجربة الثانية صنع جبن التشدر من الحليب حسب طريقة [18] وبعد اكمال خطوات التصنيع تم كبس الخثرة بدون تمليح وبعد انتهاء

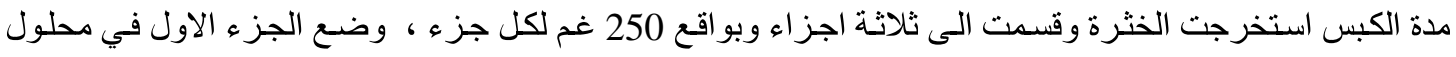

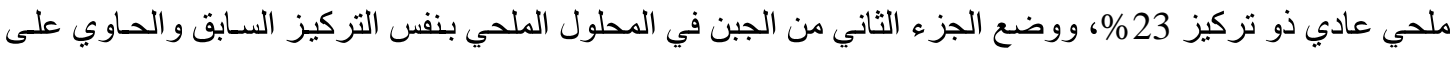

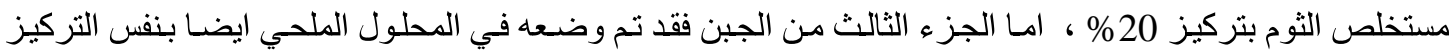

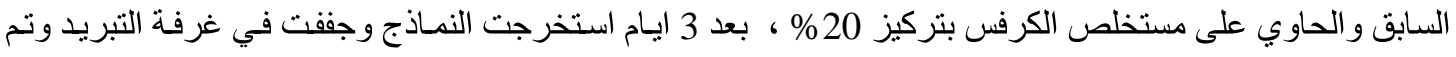

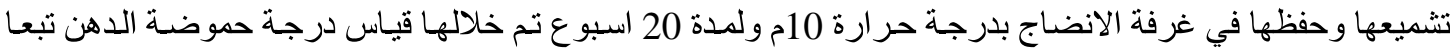

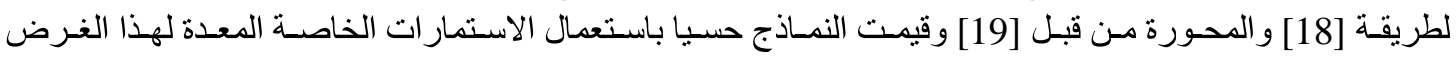

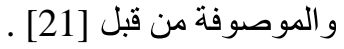

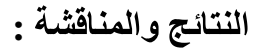

تثير النتائج في الجدول (1) إلى ان هنالك ارتفاعا غير معنوي (P>0.05) في درجـة حموضة الدهن (Acid Dgree)

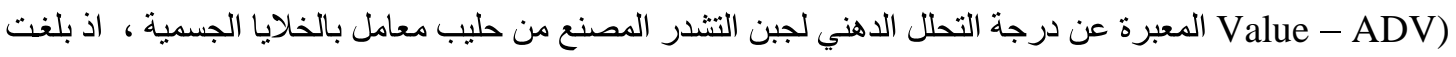

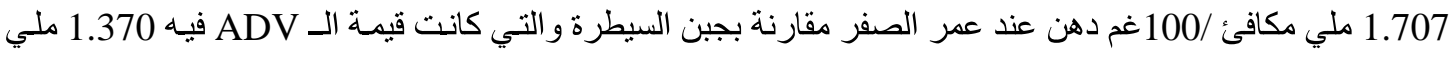

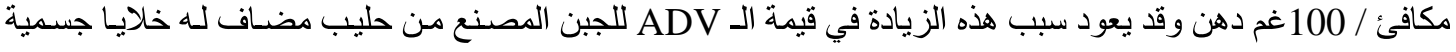

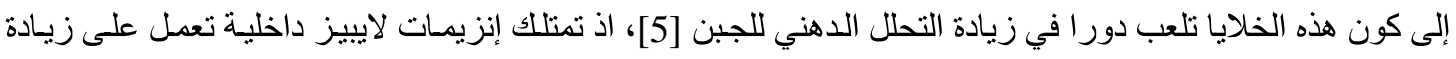

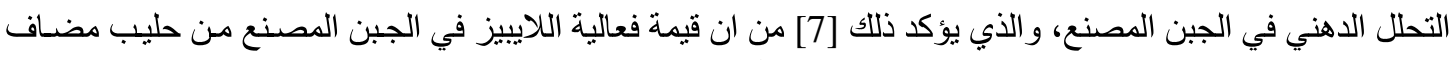

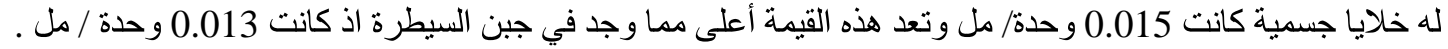
كما يظهر من الجدول نفسه حصول ارتفاع ملحوظ في قيمة

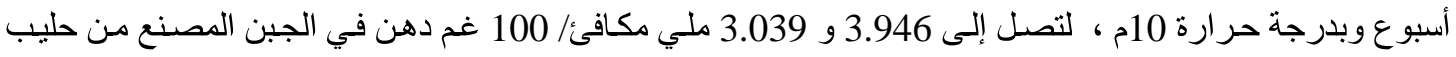


معامل بالخلايا الجسمية وجبن السيطرة تباعا في نهاية مرحلة الإنضـاج ، ويعود سبب هذا الارتفاع لنشاط الإنزيمات الإنسات

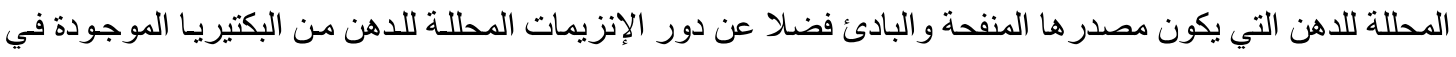

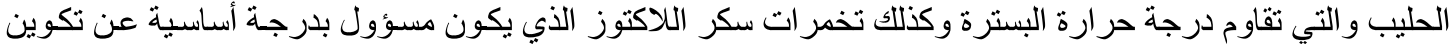

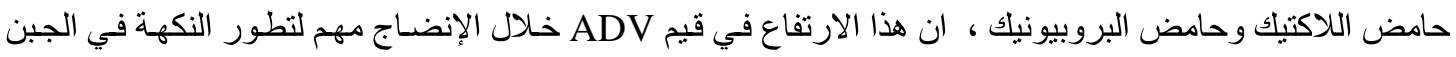

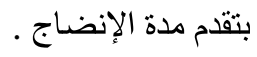

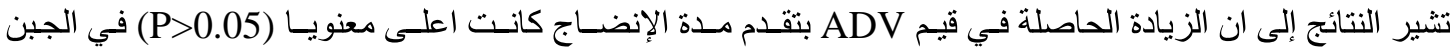

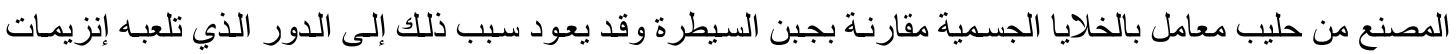

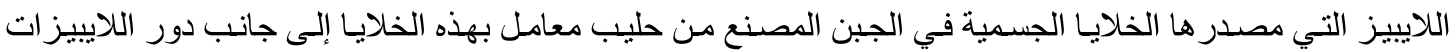
الأخرى.

جدول (1): تأثير إنزيمات اللايبيز في التحلل الدهني لجبن التثدر خلال فترة الإنضاج بدرجة حرارة 10م ولمدة 20 أسبوع "

\begin{tabular}{|c|c|c|c|c|c|c|c|}
\hline \multicolumn{7}{|c|}{ ADV ( مليمكافئ / 100 غم دهن) } & \multirow{3}{*}{ نوع الجبن } \\
\hline \multicolumn{7}{|c|}{ عمر الجبن (أسبوع) } & \\
\hline 20 & 16 & 12 & 8 & 4 & 2 & 0 & \\
\hline 3.039 & 2.966 & 2.853 & 2.103 & 1.823 & 1.430 & 1.370 & جبن السيطرة \\
\hline 3.946 & 3.779 & 3.659 & 2.715 & 2.323 & 1.823 & 1.707 & معامل مصــنع مـن حليــب \\
\hline 3.877 & 3.500 & 2.842 & 2.505 & 1.988 & 1.741 & 1.713 & جبن ذو نسبة 5\% ثوم \\
\hline 2.800 & 2.590 & 2.255 & 1.895 & 1.883 & 1.503 & 1.661 & جبن ذو نسبة 20\% ثوم \\
\hline 3.545 & 3.702 & 3.303 & 2.605 & 2.000 & 1.702 & 1.704 & جبن ذو نسبة 5\% كرفس \\
\hline 3.433 & 3.590 & 3.010 & 2.433 & 2.010 & 1.701 & 1.720 & كرفسبن ذو نســـبة 20\% \\
\hline & 0.2462 & \multicolumn{6}{|c|}{ اقل فرق معنوي للمعاملات عند مستوى احتمال 0.05} \\
\hline & 0.4606 & \multicolumn{6}{|c|}{ اقل فرق معنوي لمدة الخزن بيــن المعـاملات عند مستوى احتمال 0.05} \\
\hline & 0.6513 & \multicolumn{6}{|c|}{ اقل فرق معنوي للتداخل عند مستوى احتمال 0.050} \\
\hline
\end{tabular}

تثير النتائج أعلاه إلى إن التحلل الدهني في جبن التشدر المصنع من حليب ذو محتوى عالي من الخلايـا الجسمية كان

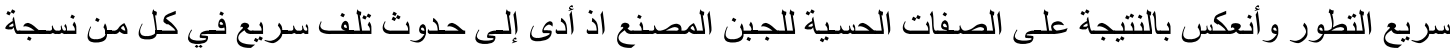

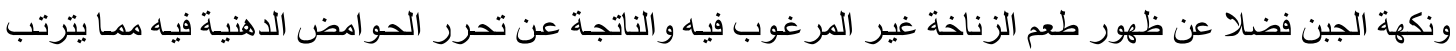

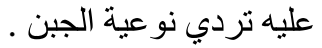

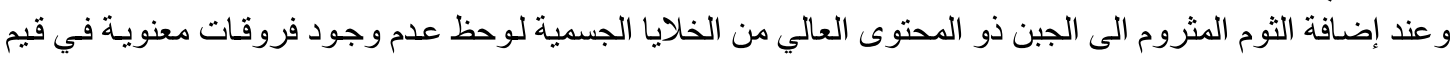

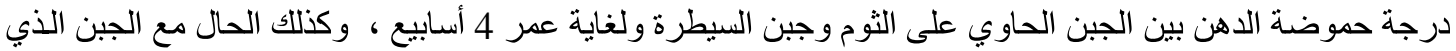

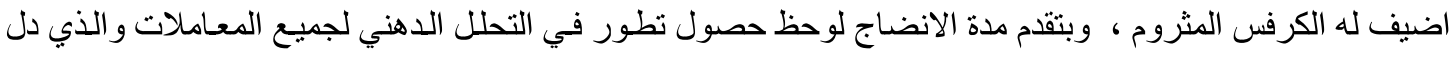

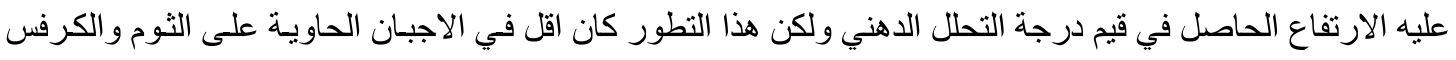

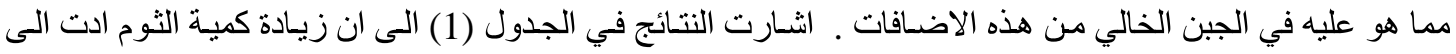

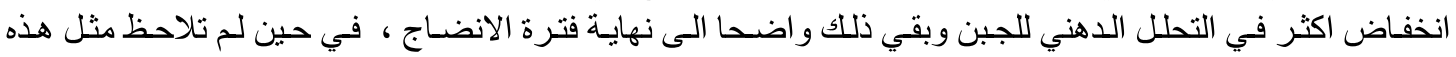

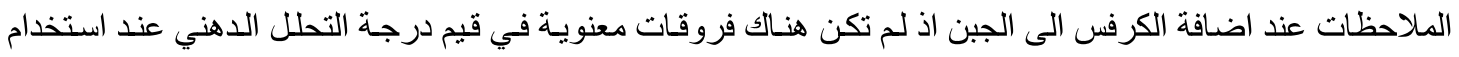
نسبة 5\% و20\% منه، مما يشير الى ان الثوم له تأثثر أكثر من الكرفس في الحد من التحلل الدهني للجبن الحساوي عليه

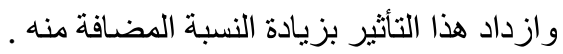

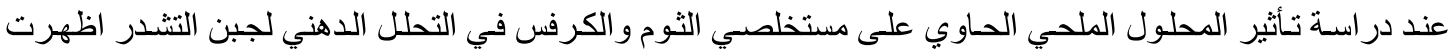

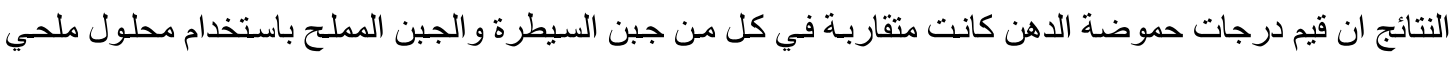

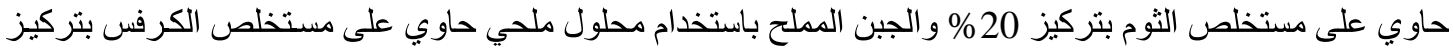

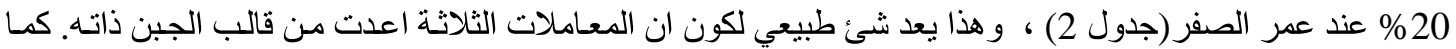

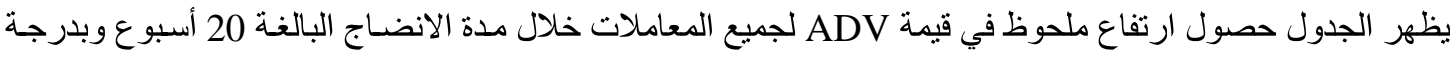




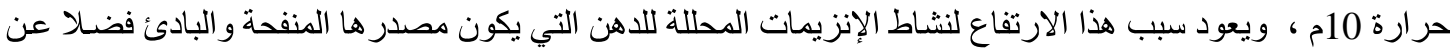

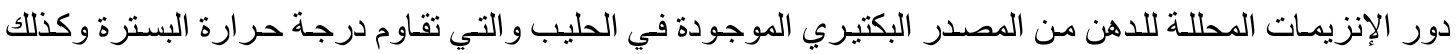

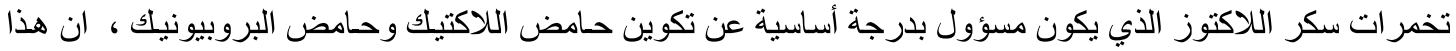

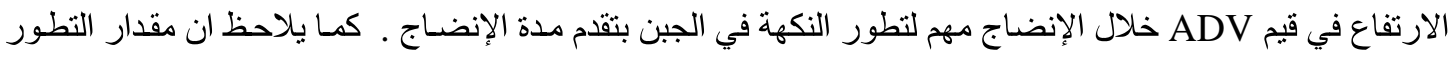

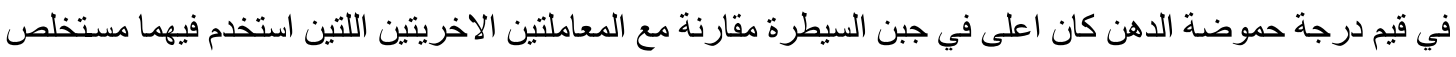

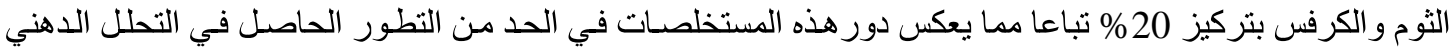

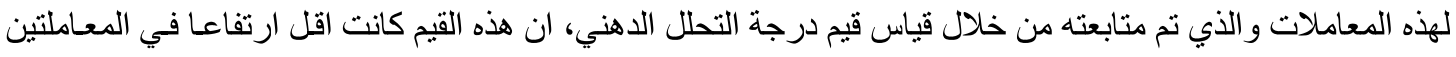

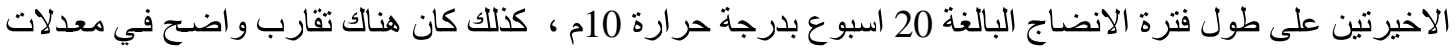

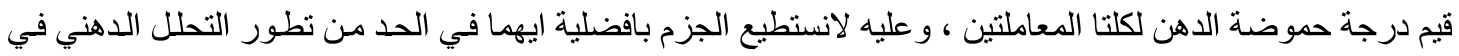
الجبن في هذه التجربة. جدول (2) تأثير المحلول الملدي الحساوي على مستخلص الثوم والكرفس في التحلل الدهني لجبن التثشدر خلال فترة الإنضاج

\begin{tabular}{|c|c|c|c|c|c|c|c|c|}
\hline \multirow{3}{*}{ 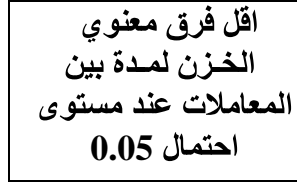 } & \multicolumn{7}{|c|}{ ADV ( مليمكافئ / 100 غم دهن) } & \multirow{3}{*}{ المعامـــة } \\
\hline & \multicolumn{7}{|c|}{ عمر الجبن (أسبوع) } & \\
\hline & 20 & 16 & 12 & 8 & 4 & 2 & $\mathbf{0}$ & \\
\hline 0.073 & 2.301 & 2.103 & 1.878 & 1.495 & 1.202 & 1.153 & 1.110 & جبن السيطرة \\
\hline 0.095 & 1.980 & 1.717 & 1.507 & 1.202 & 1.177 & 1.160 & 1.135 & 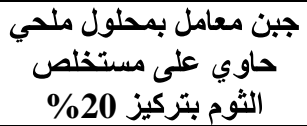 \\
\hline \multirow[t]{2}{*}{0.0695} & 2.010 & 1.878 & 1.558 & 1.191 & 1.191 & 1.150 & 1.109 & 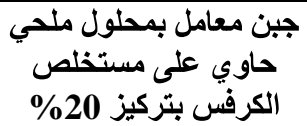 \\
\hline & 0.016 & 0.163 & 0.117 & 0.002 & 0.011 & 0.032 & 0.017 & 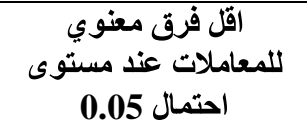 \\
\hline
\end{tabular}

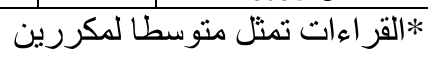

\section{التقويم الحسي للجبن}

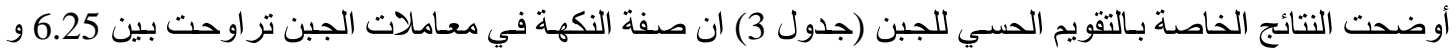

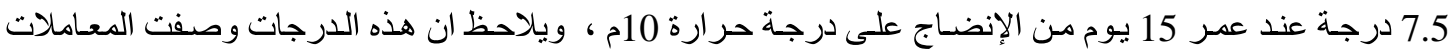

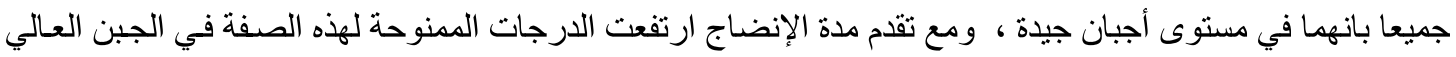

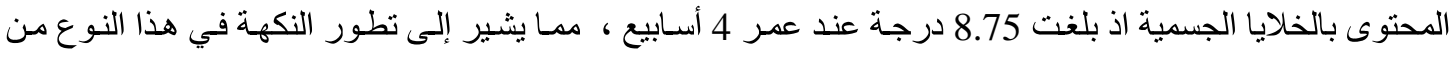

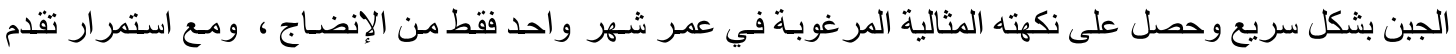

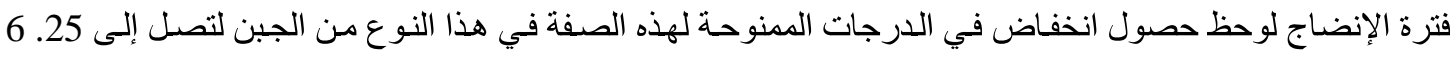

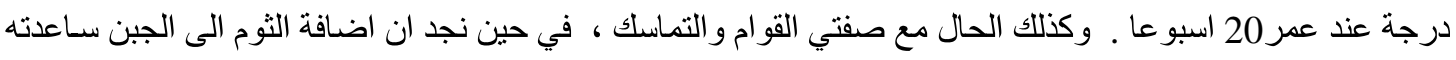

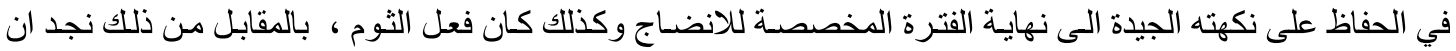

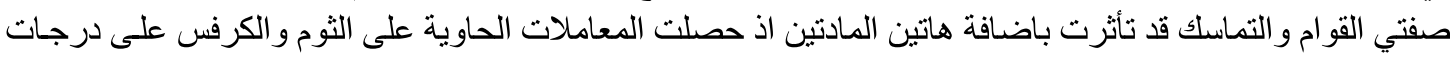

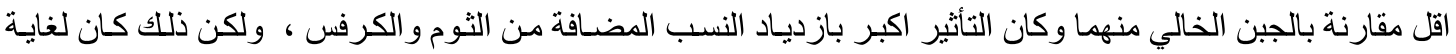

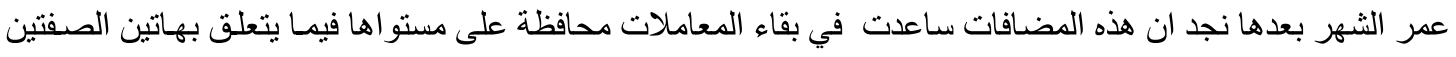

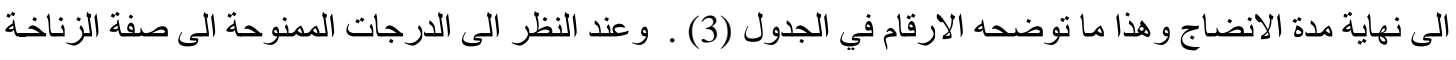

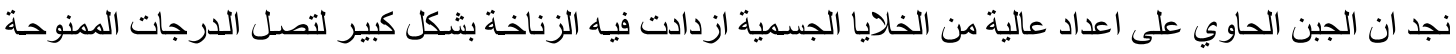

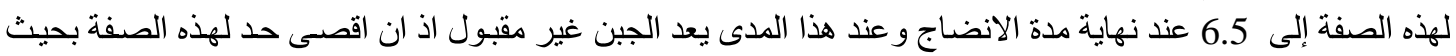

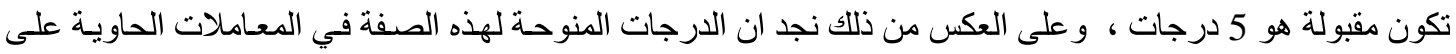

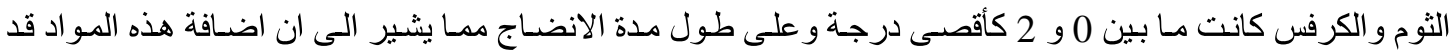




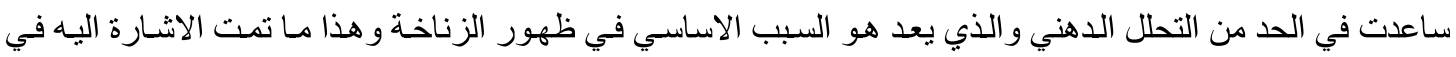

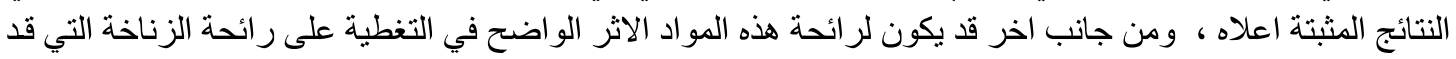

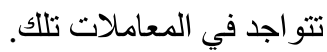

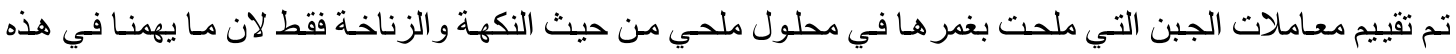

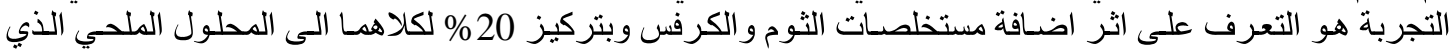

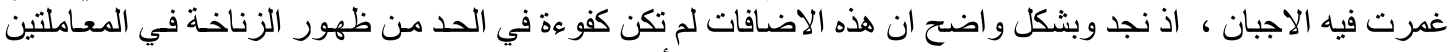

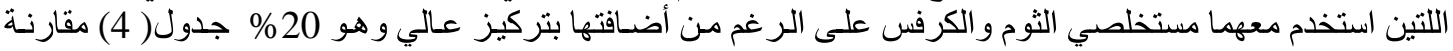

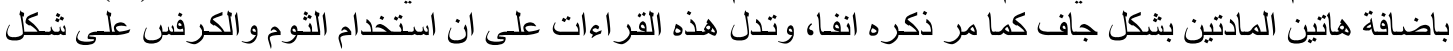

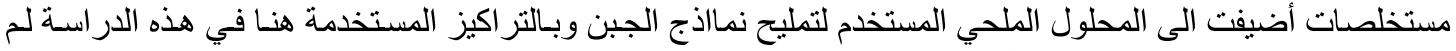

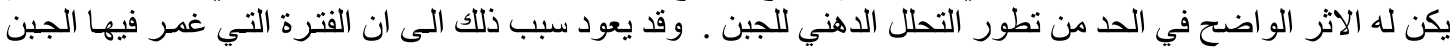

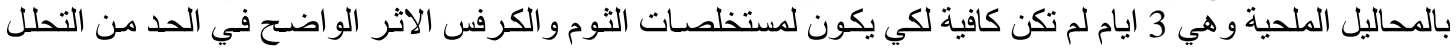

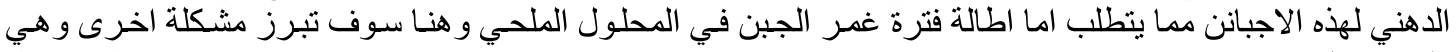

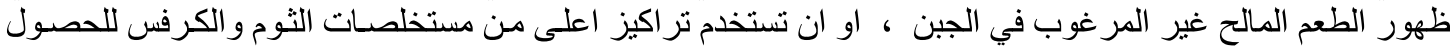
على اثر اكبر في الحد من التحلل الدهني للجبن .

جدول (3) التقويم الحسي لجبن التثدر الحاوي على اضافات من الثوم والكرفس خلال فترة الإنضاج بدرجة حرارة 10م لمدة 20

\begin{tabular}{|c|c|c|c|c|c|}
\hline \multicolumn{4}{|c|}{ الصفات } & \multirow[t]{2}{*}{ المعاملة } & \multirow{2}{*}{ عمر الجبن } \\
\hline الزناخة & التماسك & القوام & الطعم والنكهة & & \\
\hline 2 & 7.5 & 6.5 & 7.0 & جبن عالي بالخلايا الجسمية & \multirow{5}{*}{2} \\
\hline 2 & 7.0 & 6.5 & 7.0 & جبن + \%5 ثوم & \\
\hline $\mathbf{0}$ & 6.5 & 6.0 & 6.25 & جبن + 20\% ثوم & \\
\hline 1 & 7.5 & 7.0 & 7.5 & جبن + 5\% كرفس & \\
\hline $\mathbf{0}$ & 7.0 & 6.25 & 7.0 & جبن + 20\% كرفس & \\
\hline 4 & 8.75 & 9.25 & 8.75 & جبن عالي بالخلايا الجسمية & \multirow{5}{*}{4} \\
\hline 2 & 7.5 & 7.25 & 7.33 & جبن + & \\
\hline $\mathbf{0}$ & 7.25 & 7.0 & 7.0 & جبن + 20\% ثوم & \\
\hline 2 & 8.0 & 8.0 & 7.25 & جبن + 5\% كرفس & \\
\hline 2 & 7.25 & 7.5 & 7.5 & جبن + 20\% كرفس & \\
\hline 6.5 & 7.5 & 7.5 & 6.25 & جبن عالي بالخلايا الجسمية & \multirow{5}{*}{20} \\
\hline 3 & 7.0 & 7.0 & 8.0 & جبن + \% \% ثوم & \\
\hline 2 & 7.0 & 7.0 & 7.5 & جبن + 20\% ثوم & \\
\hline 4 & 8.0 & 7.5 & 7.0 & جبن + 5\% كرفس & \\
\hline 4 & 7.33 & 7.25 & 7.0 & جبن + 20\% كرفس & \\
\hline 0.275 & 0.545 & 0.483 & 0.414 & \multicolumn{2}{|c|}{ 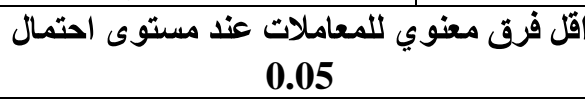 } \\
\hline
\end{tabular}


جدول (4) التقويم الحسي لجبن التثدر المملح بطريقة التمليح الرطب خلال فترة الإنضاج بدرجة حرارة 10م لمدة 20 أسبوع *.

\begin{tabular}{|c|c|c|c|}
\hline \multicolumn{2}{|c|}{ الصفات } & \multirow{2}{*}{ المعاملة } & \multirow{2}{*}{ عمر الجبن } \\
\hline الزناخة & الطعم والنكهة & & \\
\hline 2 & 7.25 & جبن عالي بالخلايا الجسمية & \multirow{3}{*}{2} \\
\hline 2 & 7.5 & جبن + 20\% ثوم & \\
\hline 2 & 7.0 & جبن + $20 \%$ كرفس & \\
\hline 5 & 8.5 & جبن عالي بالخلايا الجسمية & \multirow[b]{3}{*}{4} \\
\hline 3 & 7.5 & جبن + 20\% ثوم & \\
\hline 4 & 7.5 & جبن + 20 \% كرفس & \\
\hline 6 & 7 & جبن عالي بالخلايا الجسمية & \multirow[b]{3}{*}{20} \\
\hline 4 & 7.5 & جبن + 20\% ثوم & \\
\hline 5 & 7.0 & جبن + 20\% كرفس & \\
\hline 0.6569 & 0.6165 & \multicolumn{2}{|c|}{ اقل فرق معنوي للمعاملات عند مستوى احتمال 0.05} \\
\hline
\end{tabular}

1. Pavia, M.; Trujillo, A. J.; Sendra, E.; Guamis, B. And Ferragut, V. 2000. Free fatty acid content of Manchego - type cheese salted by brine vacuum impergnation. Int. Dairy J. 10: $563-568$.

2. Mckay, D. B.; Dieckelman, M. and Beacham, I. R. 1995. Degradation of triglyceride by a Pseudomonad isolated from milk: The roles of Lipase and esterase studied using recombinant strains over-producing or specifically deficient in these enzyme. J. Appl. Bacteriol. 78(3): 216-233.

3. Saxena, R. K.; Ghosh, P. K.; Gupta, R.; W.; Davidson, S.; Bradoo, S. And Gulati, R. 1999. Microbial Lipases: Potential Biocatalysts for the future industry. Current Science. 77(1): 101-151

4. Cernla, E.; Palocci, C. and Sorda, S. 2000. Solvent engineering modulates stereoselectivity of microbial lipases. In: Protein Engineering in Industrial Biotechnology.(ed. Lilia A.). pp: 135-146. Harwood academic publishment.

5. Jaggi, J. J.; Govindasamy - Lucey, S.; Berger, Y. M.; Johnson, M.E.; McKusick, B. C.; Thomas, D. L. and Wendorff. W. L. 2003. Hard Ewe's Milk cheese manufactured from milk of three different groups of somatic cell counts. J. Dairy Sci., 86: 3082-3089.

6. Grandison, A. S. and Ford, G. D. 1986. Effects of variations in somatic cell count on the rennet coagulation properties of milk and on the yield, composition and qualitu of cheddar cheese. J. Dairy Res.,V. 53: P. 645-655.

7. الموسوي، ازهـار جو اد. 2007. تنقيـة وتوصيف لايييز ات الخلايـا متعدة الانويـة

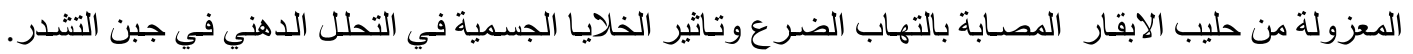

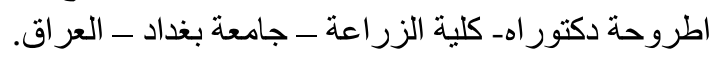

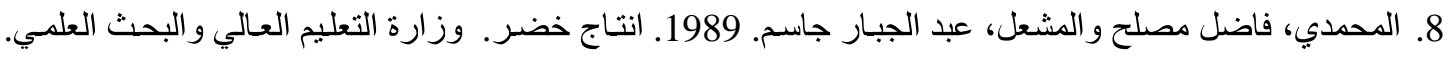

9. McGee, H. (2004). On Food and Cooking (Revised Edition). Scribner. ISBN Leeks 0684-80001-2. pp 310-313: The Onion Family: Onions, Garlic,. 
10. Lindsey, J.; Macpherson, B. H.; Geierstanger, V. V.; Michael B.; Samer R. E.; SunWook, H. and Ardem, P. 2005. "The pungency of garlic: Activation of TRPA1 and TRPV1 in response to allicin". Current Biology 15 (May 24): 929-934.

11. Horie, T.; Awazu, S.; Itakura, Y and Fuwa, T. 1992. Identified dially polysulfides from an aged garlic extract which protects the membranes from lipid peroxidation planta Medi. 58: 5, 468-469

12. Lmai, J.; Ide, N.; Nagae, S.; Moriguchi, T. And Itakura, Y. 1994. Antioxidant and Radical scavenging effects of aged garlic extract and its constituents, planta med., 60: $417-420$

13. EL-Zeini. S. And Atta, A. H. 1997. Antibacterial and antioxidant effect of crude Garlic extract in heat.Vet. Med. J., Giza. Vol. 45, No. 1: 37-45.

14. Tyneck, Z. and Szymone, A. 1971. The effect of cortion SH group inhibitors on the growth and respiration of Staphylococcus strain. Annales univ. Maricae crie - shlodo wska., 27: 59.

15. Saniewska, A. 1997. Use of garlic in protecting Antirrhium majus against Puccinia antirrhini Diet. Et hollow. plant prot. Comm. Pol. Acad. of Sci., 130 - 132.

16. Salih, A. M. A. 1978. Factors effecting lipolytic activity in cows milk. Ph. D. Thesis, Faculty of Agric., Dept. of Food Sci. Univ. Of Reading, England.

17. Azzara, C. D.and Dimick, P. S. 1985. Lipolytic enzyme activity of macrophages in bovine mammary gland secretion. J. Dairy Sci., 68:

18. الدهان، عامر حميد سعيد. 1983. صناعة الجبن و انواعه في العالم. الطبعة الاولى. مطبعة دار الحكمة. جامعة

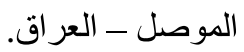

19. Frankel, E. N. and Tarassuk, N. P. 1955. The specificity of milk lipase. 11 Kinatics and relative lipolytic activity in different milks. J. Dairy Sci. 39: 1517.

20. Al- Darwash, A. K. 1982. Changes in the characteristic of cheese. Ph. D. Thesis. Faeulty of Since. University of Glasgow. U. K.

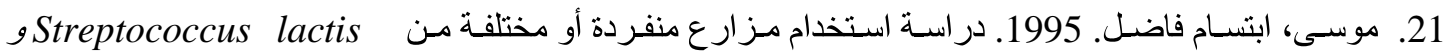

Streptococcus cremoris

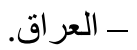

22. Bier, M. 1955. Lipases. In methods in Enzymology., Vol. 1 (ed. By Sidney, P.Colowich and Nathano, O. Kaplan). Academic press, New York, San Francisco, London.

23. Gomori, G.; 1955. Preperation of buffer for use in enzyme studies. In methods in Enzymology., Vol. 1. Academic Press, NewYork, Sanfrancisco, London. 